\title{
IDENTIDADE E MIGRAÇÃO EM ÁREAS TRANSFRONTEIRIÇAS
}

\author{
ROGÉRIO HAESBAERT \\ Universidade Federal Fluminense \\ $\mathrm{e}$ \\ MARCELO DE JESUS SANTA BÁRBARA*
}

Um dos processos sociais contemporâneos que dá maior relevância ao estudo da dimensão cultural é aquele que envolve a dinâmica migratória, cada vez mais destacada no cenário mundial globalizado. O Brasil, visto como um país imune aos dilemas étnico-culturais que afetam o mundo nas últimas décadas, e os brasileiros, às vezes até enaltecidos como exemplos de "democracia racial", pareciam alheios ao grande debate sobre o "poder da identidade" (Castells, 1999) e os grandes fluxos migratórios desse final de milênio.

Estávamos enganados: não só o mito da democracia racial há muito vem sendo questionado, como não éramos de forma alguma imunes aos grandes fluxos migratórios (tanto de imigração quanto de emigração) e às grandes questões de ordem cultural envolvendo esta dinâmica da população. O maior peso, entretanto, é dado à questão da emigração, estimando-se hoje em cerca de dois milhões os brasileiros residindo fora do país, um terço dos quais nos países fronteiriços, especialmente aqueles pertencentes ao bloco econômico do Mercosul, área que será aqui analisada.

Se não enfrentamos grandes problemas onde a dimensão étnico-cultural esteja presente de forma relevante, pelo menos a mídia se encarrega de propagandear, em meio aos nossos migrantes transfronteiriços, um "clima de limpeza étnica". Foi o que a revista Veja em 18 de agosto de 1999, ao se reportar à questão dos migrantes "brasiguaios" no Paraguai, onde a municipalidade de San Alberto está a cargo primeiro prefeito brasileiro naquele país. Justamente nessa ocasião visitamos Alberto e pudemos verificar in loco as contradições e ambigüidades do processo envolvendo um discurso "anti-brasileiro" no Paraguai.

Assim, revela-se mais do que pertinente um estudo que associe estes dois processos: a transformação das identidades culturais e as migrações transfronteiriça. O presente trabalho será desenvolvido em torno da discussão a respeito da relevância da identidade cultural enquanto realidade e/ou concepção pertinente na compreensão dos complexos processos de migração transfronteiriça, entendendo o migrante não apenas enquanto um sujeito econômico e um ente político, mas como um agente (inter)cultural ou (inter)identitário.

Estruturamos o trabalho em duas partes: a primeira, uma discussão teórica sobre cultura e identidade social; e a segunda, uma análise do processo migratório brasileiro nos vizinhos do

\footnotetext{
* Mestre em Geografia pela Universidade Federal Fluminense, prof. do Coégio Militar do Rio de Janeiro.
} 
Mercosul e, neste contexto, a importância adquirida pelo jogo de identidades na transformação do território, enfatizando o caso, mais relevante, migrantes brasileiros no Paraguai e sua ambivalente condição de "brasiguaios".

\section{Cultura: diferentes perspectivas}

A palavra cultura é polissêmica. No seu sentido mais reducionista pode aplicarse ao campo das artes (domínio reservado aos "Ministérios da Cultura" mundo afora) ou referir-se à educação e polidez dos homens "cultos". A sua origem encontra-se no termo latino colere que significava habitar ou ocupar a terra para tomá-la mais útil e agradável ao homem. Daí a palavra agri-cultura como o cultivo e o cuidado humano para com as plantas e os animais. Com efeito, expressava o necessário grau de enraizamento e a mítica superação da "herança natural" do ser humano pela prática da "cultura da terra".

A partir do século XVIII, principalmente entre os autores franceses,.o termo cultura passou a confundir-se com a noção, muito mais difundida, de civilização e, por conseguinte, passou a trazer em seu bojo a ideologia da evolução, do progresso e do racionalismo instrumental do homem branco europeu‥ A cultura, que para os estudiosos alemães enfatizava o caráter particularista das sociedades, passou a ser algo extensivo a toda a humanidade, diferenciando-se, no entanto, em termos de uma hierarquia universal de valores. Uma concepção etnocêntrica da cultura, através da qual as coletividades humanas eram definidas como "superiores" ou "inferiores", passou a separar o mundo dos "primitivos" do mundo dos "civilizados" (ou, de certa forma, "cultos").

A cultura, em seu sentido mais amplo, também se confunde com a sociedade para expressar-se através da fórmula sociedade (ou cultura) "versus" natureza. No paradigma newtonianocartesiano encontramos o homem moderno, a "cultura moderna", investido da missão de dominar a natureza. Atualmente, cogita-se que o conceito de cultura seja uma invenção, um recurso analítico usado pelos antropólogos, tanto para interpretar as experiências de sua sociedade quanto as das "outras".

Para Latouche (1996), a cultura é a resposta que os grupamentos humanos dão ao problema de sua existência social. Com o advento da sociedade informacional ou pós-moderna, o questionamento das grandes visões de mundo racional-evolucionistas e o peso crescente adquirido pela produção de imagens e representações ou, num sentido mais amplo, pelo mundo da linguagem e dos significados, levou a uma valorização da dimensão simbólica que, para muitos, passou a ser uma questão central, através dos chamados estudos culturais. O homem, regido pela produção de signos e imagens, se dirige para as questões culturais com uma ênfase nunca vista. Ao mesmo tempo, a perda de sentido de uma vida cada vez mais instrumentalizada e mercantilizada leva-o a voltar-se para a re-construção de valores e identidades capazes de lhe proporcionar um novo sentido para a existência.

\section{A questão da identidade}

O conceito de identidade pode ser analisado em diferentes campos disciplinares, aparecendo vinculado a três perspectivas básicas: no âmbito da filosofia, como princípio lógico; da

1Elias (1994[ 1939]) dedica o primeiro capítulo de seu livro "Q processo civilizador" à "sociogênese da diferença" entre "cultura" e "civilização", a primeira muito mais presente no mundo cultural "nacionalista" alemão, a segunda no mundo de pretensóes mais "universalistas" de língua inglesa e francesa: "Enquanto o conceito de civilização inclui a função de dar expressão a uma tendência continuamente expansionista de grupos colonizadores, o conceito de Kultur reflete a consciência de si mesma de uma nação que teve de buscar e constituir incessante e novamente suas fronteiras. (...) e repetidas vezes perguntar a si mesma: Qual é, realmente, a nossa indentidade?"' (p. 25) 
psicologia, enquanto identidade individual ou pessoal, e na antropologia ou nas ciências sociais em geral, numa perspectiva relacional, frente à alteridade (HAESBAERT, 1999). É este último sentido que nos interessa neste trabalho.

As identidades, pelo viés antropológico, são construídas historicamente pelos sujeitos na relação e interação espaço-temporal com a alteridade, com o Outro. Segundo Lévi-Strauss (1977:333), que destaca o caráter simbólico da identidade, a diversidade das culturas é "menos função do isolamento dos grupos que das relações que os unem". O processo de constituição identitária de um grupo, portanto, é sempre de caráter relacional. Ocorre, por isso mesmo, a partir da relação entre os que de algum modo são classificados e re-conhecidos como semelhantes (mas não idênticos) e os "outros". Conforme Todorov (1993), torna-se essencial sabermos se nessa relação existem valores culturais universais, que não têm fronteiras, ou se todos os valores são relativos:

O etnocêntrico é, por assim dizer; a caricatura natural do universalista: este, em sua aspiração universal, parte de um particular, que se empenha em generalizar; e tal particular deve forçosamente lhe ser familiar, quer dizer, na prática, encontrar-se em sua cultura.(...) o etnocentrismo tem, portanto, duas facetas: a pretensão ao universal, de um lado, o conteúdo particular (o mais freqüentemente nacional) de outro... $(1993: 21,22)$

Uma segunda discussão importante, que é inerente à concepção antropológica e/ou sociológica de identidade, envolve também a relação entre indivíduo e sociedade. Nos termos de Berger e Luckman (1983), a identidade social é um fenômeno reconhecido através da dialética entre o indivíduo e a sociedade. A identidade de um indivíduo ou grupo é "um elemento chave da realidade subjetiva, e tal como toda realidade subjetiva, acha-se em relação dialética com a sociedade". A subjetividade individual, de acordo com esses autores, deve ser vista de forma contextualizada, ou seja, o indivíduo está em interação com a estrutura social de modo que toda a interpretação sobre sua identidade tem de estar "localizada em um mundo social". É este fato que nos possibilita trabalhar com o conceito de identidade coletiva, sem que se estabeleça uma dicotomia entre o indivíduo e o contexto social do qual faz parte.

De acordo com Cardoso de Oliveira (1976), o núcleo do conceito de identidade étnica está no fato de ela ser contrastiva. Isto significa dizer que é por contato, isto é, através de interações espaciais que uma pessoa ou grupo se identifica como tal, passa a visualizar o "outro" de forma etnocêntrica. Esse autor desenvolve tal perspectiva ao trabalhar com o estudo dos contatos interétnicos ("fricção interétnica") em áreas de expansão da fronteira demográfica e econômica da "civilização" na Amazônia.

Falar em fronteira é falar do universo empírico deste trabalho, na medida em que nos dedicamos a estudar as áreas transfronteiriças entre o Brasil e os vizinhos do Mercosul. Martins (1997), embora tratando não especificamente de fronteira no sentido político, mas sobretudo numa percepção econômica, demográfica e cultural, afirma que a realidade de fronteira representa não só o desencontro de diferentes visões de mundo, como também, por conseguinte, a coexistência de diferentes espaço-temporalidades. Esta "contemporaneidade da diversidade" é a responsável pela definição tanto da individualidade quanto da identidade dos agentes sociais aí envolvidos. Desta forma:

(...) a fronteira é essencialmente o lugar da alteridade. É isso que faz dela um lugar singular: À primeira vista é o lugar de encontro dos que, por diferentes razões, são diferentes entre si, como os índios de um lado e os civilizados do outro; como os grandes proprietários de terra, de um lado e os camponeses pobres, de outro. Mas o conflito faz com que a fronteira seja essencialmente, a um só tempo, um lugar de descoberta do outro e de desencontro. (MARTINS, 1997:150)

Partimos da premissa de que a construção de identidades (sociais, étnicas, culturais, 
territoriais etc.) é um processo indissociavelmente ligado a contextos marcados por relações de poder simbólico que, no caso das fronteiras, sejam elas políticas ou econômico-culturais, fica ainda mais pronunciado. Uma representação social ou um símbolo tem papel fundamental de legitimação à medida que passa a ser conhecida e reconhecida como verdadeira por aqueles que lhe estão sujeitos ou que a constróem. Por isso, nas palavras de Pierre Bourdieu:

O poder simbólico é um poder de construção da realidade que tende a estabelecer uma ordem gnoseológica: o sentido imediato do mundo (e, em particular; do mundo social) supõe aquilo que Durkheim chama de conformismo lógico, quer dizer, 'unia concepção homogênea do tempo, do espaço, do número, da causa, que torna possivel a concordância entre as inteligências (1996:9)

O que temos em jogo com o poder simbólico é a imposição de um modo de apreensão do mundo social, que configura a "naturalização" de uma ordem social vigente. Podemos nos questionar a serviço de quem está o poder. Quem são os excluídos pelo poder? O poder simbólico é uma forma transformada ou mascarada de outras formas de poder, notadamente o poder econômico e político; todavia, não se trata simplesmente de uma dominação estritamente consciente, maniqueísta ou intencional. Ele, freqüentemente, é ignorado e apreendido como arbitrário por quem o exerce.

O domínio de um princípio de di-visão do mundo sobre outros, como, às vezes nos dá a entender Bourdieu, não é um ciclo vicioso incapaz de admitir resistências ou pontos de clivagem. A globalização, ou como afirma Castells (1999). a emergência da "sociedade em rede", é um processo caracterizado, dentre outras coisas, por reestruturações no capitalismo e pela derrocada do socialismo realmente existente. Esse contexto tem sido o pano de fundo da emergência de vários movimentos sociais ou de identidades coletivas de resistência com bases locais. Estas buscam se opor ao "cosmopolitismo global" em benefício de singularidades e do direito de controlar suas vidas e seus ambientes.

Castells define identidade como sendo a "fonte de significado e experiência de um povo" (1999:22). O significado é o eixo em torno do qual os atores sociais estruturam sua identidade de modo que ela seja capaz de se auto-sustentar no tempo e no espaço. Conseqüentemente, a geografia, a história, a biologia etc. fornecem a matéria-prima para o processo em questão. Embora do ponto de vista sociológico/antropológico toda identidade seja uma construção abstrata, é importante que estejamos atentos às razões de sua existência. Atualmente parece viável afirmar que identidades não podem ser entendidas sem a sua correspondente dimensão políticoestratégica e, em grande parte, também, territorial. Para Bayart (1996) o que existe, sempre, são "estratégias identitárias", ou seja, a mobilização política das identidades culturais. Isto ficará claro em nossa análise da ativação que os migrantes brasileiros fazem, no Paraguai, de sua condição de "brasiguaios".

A dinâmica anteriormente referida sinaliza para o fato de que não podemos mais enfocar a identidade de um grupo de forma abstrata e nem tampouco vê-la dotada de uma essência imutável. Toda identidade deve ser contextualizada, o que significa ter um espaço e tempo de referência. Sendo assim, ainda de acordo com Castells, uma identidade que hoje se organiza como identidade de resistência, minoritária, pode almejar tornar-se uma identidade de projeto, transformadora, e, por conseguinte, ao se ampliar, tornar-se legitimadora de uma determinada ordem social. Com efeito, tende assim a racionalizar um domínio que torna-se-á mais amplo e eficaz à medida que não precise usar a força ou a violência física para se manter. Dando contornos finais a esta visão teórica sobre o conceito de identidade, vamos nos deter rapidamente nas concepções de "identidade híbrida" e "identidades plurais", por considerá-las muito importantes na análise da realidade empírica abordada na segunda parte do texto.

Stuart Hall (1997), em seu livro "Identidades Culturais na Pós-Modernidade", defende a tese de que as identidades modernas estão em crise. As "identidades modernas" estão sendo 
descentradas, deslocadas ou fragmentadas pela globalização em seus impactos sobre os referenciais modernos de sujeito, tempo e espaço. De acordo com o autor, todavia, existem três classificações ou contra-tendências à homogeneização cultural global. A globalização caminha paralelamente ao refortalecimento de identidades locais, o que não impede que o fascínio com a diferença, com o "étnico" e com a alteridade, se insira dentro de uma lógica mercantil, pois "diversidade vende", criando novos nichos de mercado.

O processo de expansão do sistema capitalista a nível mundial retém vários aspectos da dominação global ocidental e as identidades culturais estão sendo, em toda parte, relativizadas pelo impacto da compressão espaço-tempo. As relações entre o global e o local são redefinidas, propiciando o surgimento de novas identidades globais e locais, ou as duas ao mesmo tempo (naquilo que Robertson [1999] denomina "glocalização"). A globalização, em síntese, ocasiona um efeito deslocador e descentralizador de identidades organizadas em torno de uma cultura e de fronteiras bem definidas (especialmente as fronteiras nacionais), criando novas posições de identificação, mais plurais, menos unitárias e fixas.

O indivíduo híbrido é aquele que provém do cruzamento de culturas diferentes, composto por elementos de origens diversas, um indivíduo mesclado. A noção de hibridismo, comum à genética, remete à idéia de uma mistura que contraria a "natureza" ou a ordem natural das coisas. Latour (1996) utiliza o termo para se referir às diversas tramas que têm sido cotidianamente delineadas entre a natureza e a cultura, o global e o local. Para o autor, contudo, estes "híbridos" continuam sendo considerados em um segundo plano, ignorados pelas análises da modernidade. Quanto mais proliferam os híbridos, menos admitimos e analisamos a sua existência. A proposta, porém, é reatar o "nó górdio" que une essas dimensões do real. Para isso, diz ele:

(...) nosso meio de transporte é a noção de rede ou tradução. Mais flexível que a noção de sistema, mais histórica que a de estrutura, mais empirica que a de complexidade, a rede é o fio de ariadne destas histórias confusas. (LATOUR, 1996:9)

A idéia de "sujeitos traduzidos" — termo originário do latim que significa transferir ou transportar através de fronteiras - define bem, segundo Stuart Hall, a situação de migrantes que acabam sempre construindo identidades híbridas. A medida que os indivíduos venham a pertencer a dois mundos ao mesmo tempo, eles procuram manter, conflituosamente, suas raízes, suas tradições e a memória que os ligam a um território de origem. Por outro lado, são impelidos a novos diálogos pela necessidade de reconstruírem suas identidades em meio aos novos territórios e culturas com as quais passam a ter contatos cotidianos. Assim, o conceito de tradução:

(...) descreve aquelas formações de identidades que atravessam e intersectam as fronteiras naturais compostas por pessoas que foram dispersadas (migrantes) para sempre de sua terra natal. (...) [Elas] retêm fortes vínculos com seu lugar de origem e tradições, mas sem a ilusão de retorno ao passado. Elas são obrigadas a negociar com as novas culturas em que vivem, sem simplesmente serem assimiladas por elas e sem perder completamente a sua identidade. (...) devem aprender a habitar no mínimo duas identidades, a falar duas linguagens culturais, a traduzir e negociar entre elas. (1996:95)

A presente reflexão aponta para o fato de que as identidades mudam de acordo com o contexto espaço-temporal ou o modo como o sujeito é conhecido e reconhecido. Neste caso, adotamos mais a noção de processos de identificação do que de identidade enquanto um "estado" ou condição, dotada de estabilidade. Se em tempos de globalização, conforme defende Hall, não existe mais um único foco de identificação, uma "identidade mestra" capaz de polarizar os diversos interesses e demandas dos sujeitos, as identidades tornam-se plurais. Elas podem ser ganhas ou perdidas, posto que estão fragmentadas, interna e externamente aos sujeitos, em múltiplos pólos e estratégias de poder nem sempre conciliáveis entre si.

Nesse meio volátil, contudo, nem tudo são identidades híbridas, e um dos indicadores fundamentais da complexidade dessa dinâmica que gera ao mesmo tempo hibridismos e 
"integrismos" é a relação que os grupos sociais estabelecem com os seus territórios para a construção de suas identidades. Em parte como uma forma de evitar a instabilidade do cosmopolitismo ou uma certa indefinição dos hibridismos, muitos grupos se refugiam sob a tutela de "fronteiras territoriais" rígidas para manter a coesão de seus enraizamentos.

A identidade territorial é um tipo de identidade social que se expressa na relação de pertencimento de um grupo a partir da delimitação de uma escala territorial de referência identitária (HAESBAERT:1988, 1997). Neste sentido, também entendemos os processos de construção de identidades territoriais a partir de uma perspectiva contrastiva/relacional, pois estas são construídas e mobilizadas na interação entre grupos sociais. Embora no senso comum, tanto uma identidade territorial como, por exemplo, a identidade nacional, quanto uma divisão territorial como o Estado-nação, possam ser tomadas como fatos naturais - o que Bourdieu (1997) chama de visão substancialista — partilhamos da tese de que as identidades são sempre construções sociais, históricas.

Mesmo que vejamos as identidades ou símbolos, conforme Hobsbawm (1984), dentro de um sistema de "tradições inventadas," podemos dizer que elas não são simples abstrações, posto que também são materialmente representadas, e estas representações materiais - como o próprio território - compõem de forma indissociável o jogo de sua construção. À medida que elas têm como fonte de significado, geografias e histórias "imaginárias" ou "reais", podem fornecer quadros para a ação social dos agentes que através delas se reconhecem ou são reconhecidos como legítimos.

A imposição de princípios de divisão (demarcação e representação) do espaço ocorre através da incorporação, por parte de indivíduos e grupos, de uma "estrutura de diferenças objetivas". Estas são expressas geograficamente, por exemplo, pela posse ou pelo domínio de fontes de reprodução social como a terra, ou através da correlação entre os valores auto-atribuídos a um grupo social e a re-produção de um ambiente local. À medida que essa visão de mundo passa a ser partilhada individualmente por todos os agentes, estes irão estruturar suas percepções e valores sociais a partir do ponto de vista e dos referenciais materiais da cultura dominante.

O processo anteriormente descrito, uma vez que também se baseia na dominação econômica e no controle político do território, suscita, por oposição, a construção de identidades territoriais de resistência. Este tipo de identidade é mobilizado por grupos que, conscientes da situação de exclusão à qual estão submetidos, passam a entrincheirar-se de modo a fazer referência ao território como fonte de significado e, por isso, base fundamental para a luta. O migrante, em sua situação de desterritorializado em busca de uma nova territorialização, faz uso com freqüência desse "arsenal" de múltiplas identidades (inclusive aquelas com forte base territorial) para fazer valer seus interesses. Vejamos como isto se reproduz no caso dos migrantes brasileiros nos países vizinhos do Mercosul - Argentina, Uruguai e, especialmente, no Paraguai.

\section{A imigração brasileira junto aos vizinhos do Mercosul}

Inicialmente precisamos definir o contexto espaço-temporal em que se insere a migração brasileira nos vizinhos do Prata, a fim de, posteriormente, compreender os meandros em que se manifestam as suas identidades territoriais. É importante começar lembrando que o traçado das fronteiras entre o Brasil e os vizinhos platinos foi, durante longo tempo (especialmente ao longo do século XIX), motivo de intensas disputas.

A linha "seca" que hoje serve de limite entre o Brasil e o Uruguai demonstra bem esta maleabilidade transfronteiriça que por muito tempo tem feito dessa fronteira um território de múltiplos contatos. Localidades gêmeas como Santana do Livramento-Rivera e Chuí-Chuy revelam um limite na prática imperceptível. Mas, como se tratam de áreas fronteiriças 
demográfica e economicamente mais estáveis, a migração de brasileiros para o interior uruguaio, e, menos ainda, o de uruguaios para o Brasil, foi, até recentemente, pouco relevante. Nos anos 90, o avanço da fronteira agrícola no pampa sul-rio-grandense, através da moderna rizicultura irrigada levou milhares de empresários e trabalhadores brasileiros para o interior do pampa uruguaio (departamentos limítrofes com o Brasil) e argentino (região "mesopotâmica", especialmente as províncias de Corrientes e Entre-Ríos).

Já no caso do Paraguai e da província Argentina de Misiones, áreas de mata e terra-roxa atraíram os colonos brasileiros, especialmente do Sul, em busca de novas áreas para a agricultura. Pequenos produtores atravessaram o rio Uruguai e estabeleceram "colônias" em Misiones, como as colônias Aurora e Alicia, mas a legislação Argentina, mais rigorosa, aliada ao estabelecimento de reservas ecológicas, impediu o avanço desta migração, ao contrário do que acabou acontecendo no Paraguai. Neste país, a política governamental do ditador Stroessner, com sua "marcha para o Leste" nos anos 60, veio se somar ao interesse de empresários brasileiros que, principalmente com a expansão do complexo soja, nos anos 70, buscavam terras férteis e mais baratas para plantar. Foi assim que se desencadeou a devastação florestal do leste paraguaio, hoje quase completamente tomado pelas grandes lavouras de soja e povoado por cerca de 350 mil brasileiros (para uma estimativa de 40 mil brasileiros na Argentina e 30 mil no Uruguai).

A bibliografia consultada oferece os números mais diversos sobre a presença brasileira nesses países. No Paraguai, de acordo com Kohlhep (1999) seriam em torno de 450 mil; já Sprandel (1992) afirma que existem aproximadamente 400 mil e a Revista Época chega ao quantitativo de um milhão de brasileiros. Municípios como o de San Alberto, no Paraguai, chegam a ser apontados como "enclaves brasileiros em pleno Paraguai" (Folha do Paraná, 26/07/98). Esta municipalidade possui cerca de 25 mil habitantes, dos quais a prefeitura local estima que aproximadamente $80 \%$ sejam brasileiros.

A presença brasileira também é significativa em sua influência cultural sobre os espaços de migração, principalmente no caso paraguaio. A difusão da cultura e de costumes brasileiros faz com que emissoras de rádio, em localidades como Santa Rita e San Alberto, tenham horários onde a transmissão é feita exclusivamente em português. "Me sinto como se estivesse no Brasil, por causa da tevê parabólica e da comida", afirmou uma migrante brasileira em Santa Rita. Existem casos, principalmente entre as gerações mais recentes de brasileiros no Paraguai, em que os imigrantes mantêm a tradição de falar o alemão (segundo idioma de muitos brasileiros originários do sul do país) no âmbito das relações familiares. Já. no espaço público fala-se o português, porém na escola existe a obrigatoriedade de comunicar-se somente em espanhol e guarani. O idioma guarani, visivelmente um instrumento cultural de resistência para os paraguaios, vai sendo aos poucos introduzido na comunidade brasileira, que começa a reconhecer o seu papel estratégico nas relações sociais.

Os depoimentos a seguir dão uma dimensão a respeito da influência cultural brasileira e da difusão do idioma português no Paraguai Oriental:

Os brasileiros imitam os americanos e nós, paraguaios, imitamos os brasileiros (...) a cultura brasileira também influenciou muito o nosso modo de vestir (...) as paraguaias não usavam calça jeans antes de ver as brasileiras. (universitária paraguaia, La Paloma)

Os paraguaios tudo, tudo falam português (sic). Temo brasileiro que tem trinta, quarenta anos aqui e não sabe conversar castelhano. (...) os paraguaios falam português desde pequenininho, assistem programa da Xuxa e aprendem. Aqui pega todos os canais do Brasil. (imigrante brasileiro, La Paloma).

São os paraguaios que têm que se adaptar ao português... são poucos os imigrantes brasileiros que sentem a necessidade real de falar o castelhano. (...) aqui há paraguaios que falam português e não falam guarani. (...) por isso eu te digo que a integração aqui é total, não temos canais paraguaios porque não temos satélites. (professor paraguaio, San Alberto) 
Os limites do território paraguaio são relativizados pela influência cultural (idioma, costumes etc.) dos brasileiros, mas o fato da fronteira ser utilizada por representantes do Estado paraguaio para controlar o acesso e circulação de imigrantes brasileiros revela que ela ainda representa um importante instrumento de poder, tanto político quanto econômico. Somente nos cinco primeiros meses de 1998 foram arrecadados cerca de 850 milhões de guaranis através de taxas "legais" sobre os migrantes brasileiros, isso sem contabilizar-se as propinas (que incluem "pedágios" para indocumentados) cobradas por autoridades corruptas e, não raro, violentas ( $A B C$ Color, Assunção, 22/06/98).

A maioria dos imigrantes brasileiros não tem documentação legal ou, quando a possui, já está vencida. O processo de legalização é burocrático e caro. No câmbio de janeiro de 2001, o governo cobrava em torno de um milhão e duzentos mil guaranis (705 reais) para emitir um visto de residência no Paraguai. Já para se renovar a carteira do migrante é cobrada a quantia de seiscentos mil guaranis (352 reais). A posse da carteira do imigrante e, em conseqüência, a cidadania paraguaia, também podem ser usadas como uma estratégia que visa facilitar a sua mobilidade espacial. "Ser cidadã paraguaia não significa nada, exceto o fato de se ter liberdade para circular", disse-nos uma empresária brasileira em San Alberto. Fica claro, neste caso, a utilização desse "recurso identitário" (onde se confundem identidade nacional e cidadania política) para propósitos bastante concretos - facilitar a mobilidade, ou seja, tornar-se "paraguaio", pelo menos a nível formal, a fim de usufruir dos benefícios concretos que esta condição "cidadã" ou "legal" proporciona.

Os departamentos do Alto Paraná e de Canindeyu, tomados em conjunto, apresentam características como maior concentração de brasileiros, uso do solo ligado à soja e existência de uma incipiente rede urbana brasileira formada por cidades como Santa Rosa, Santa Rita, La Paloma, Katueté e San Alberto. Com efeito, é possível notarmos que essa "invasão brasileira" influenciou significativamente, no intervalo de 40 anos, o reordenamento territorial nos espaços da fronteira leste do Paraguai.

Para termos uma noção do ritmo das transformações territoriais implementadas no Paraguai Oriental, cerca de dois milhões de hectares de florestas foram destruidas pela expansão da fronteira agrícola brasileira (KOHLHEP, 1999; SOUCHAUD, 2000). A ambigüidade dessas ações também estão expressas nas representações ambivalentes que os paraguaios têm a respeito da presença brasileira em suas terras: "Os brasileiros são destruidores da natureza" (professora paraguaia); "sem os brasileiros os paraguaios não seriam nada, eles trouxeram o comércio e a agricultura" (dona de hotel, San Alberto).

Num olhar espacial sobre a construção de identidades na escala local, ligada ao cotidiano e aos contatos face-a-face entre brasileiros e paraguaios, o fato dos imigrantes brasileiros terem de competir individualmente e/ou coletivamente por recursos com a população paraguaia parece ser o motivo que os faz, por contraste, identificarem-se em terras paraguaias como brasileiros, mas também como "sulistas" ou "nordestinos", por exemplo. Estas múltiplas escalas de identificação apresentam fenômenos curiosos, como a divisão que encontramos na cidade de Santa Rosa, onde, no bairro mais pobre, denominado sintomaticamente de "Vila Guarani", encontramos famílias de migrantes mineiros do vale do Jequitinhonha. Estes se referiam aos moradores mais ricos do centro da cidade como "os alemães", numa alusão à origem étnica dos migrantes, provenientes da área de colonização do noroeste gaúcho.

Uma vez re-conhecidos genericamente como brasileiros, a tendência é que os imigrantes passem a ativar essa identidade de modo a realçar e legitimar uma pretensa ordem frente à população paraguaia. Assim, eles re-constróem e fazem uso de certos traços identitários como "símbolos de prestígio" (Goffman, 1988), ao mesmo tempo em que atribuem qualidades depreciativas aos paraguaios. A eficácia desse processo para a legitimação simbólica da ordem territorial estabelecida pela dinâmica de imigração brasileira fica evidente no fato de que muitos 
dos paraguaios entrevistados, além de estigmatizados pelos brasileiros, parecem reconhecer esses estigmas como verdadeiros.

A construção social da idéia de que os imigrantes brasileiros são, de um modo geral, naturalmente "trabalhadores", "disciplinados" e difusores do "progresso", em oposição aos paraguaios, que são vistos e muitas vezes se reconhecem como "preguiçosos", "desregrados" e "atrasados", é bastante difundida em municípios como San Alberto e La Paloma. A origem majoritariamente européia (alemã, italiana, polonesa etc.) de muitos dos imigrantes brasileiros pesa bastante nesse sentido.

No caso do Uruguai, encontramos situações bastante ambíguas, pois ali os migrantes brasileiros, em proporções ainda maiores provenientes da região Sul, descendentes de europeus, defrontam-se com outros povos de origem européia. A segmentação identitária mais importante, neste caso, envolve o país de origem na Europa: empresários brasileiros revelaram que preferem os trabalhadores do Rio Grande do Sul, descendentes de italianos e alemães, mais habituados à disciplina da lavoura do que os uruguaios, descendentes de espanhóis e "mais afeitos às lides do campo" (pecuária.). Eles só não lembraram que a maioria desses trabalhadores vem para o Uruguai em condição de ilegalidade, não impondo, portanto, o ônus trabalhista dos trabalhadores uruguaios.

Já pa ra uruguaios que entrevistamos na cidade de Meio, esses trabalhadores brasileiros podem também ser vistos como "a negrada", aqueles que trouxeram a bagunça" e o aumento da criminalidade. Como se percebe, os processos de identificação são sempre múltiplos ou ambivalentes. Diante do olhar do "outro" e, especialmente, quando se está na condição de migrante, a conotação pode mudar com relativa facilidade: por exemplo, num contexto de crise econômica, passa-se rapidamente de migrantes altamente prestigiados para migrantes profundamente estigmatizados. Tudo depende das relações econômico-políticas em que os grupos estão inseridos.

A "dominação" ideológico-cultural brasileira sobre a população dos vizinhos do Prata tende a dar uma falsa idéia de homogeneidade social entre o grupo migrante e entre os próprios paraguaios, uruguaios e/ou argentinos. Esses sujeitos, na verdade, também re-constróem nos países vizinhos, além da identidade nacional brasileira, distinções quanto à classe social (semterras; pequenos, médios, grandes proprietários; empresários etc.); identidades regionais (sulistas, nordestinos etc.), traços étnicos (descendentes de alemães, italianos, poloneses, negros, índios etc.). Tais atributos dão idéia da pluralidade de possibilidades ao alcance de um imigrante brasileiro para que esse reconstrua sua identidade social em terra estrangeira, tanto pela autoreconstrução de sua imagem quanto pelas atribuições que lhe são dadas pelos outros grupos nacionais, étnicos e regionais.

Um exemplo que define claramente esse processo de pluralidade identitária nos foi dado pela análise de como os imigrantes brasileiros ativam e transitam pela identidade "brasiguaios". Constatamos que essa identidade social pode ser ativada por diferentes agentes sociais como um recurso político que varia de acordo com os interesses em jogo em um determinado contexto espaço-temporal.

A emergência da identidade "brasiguaios" (SPRANDEL, 1996), ao contrário do que indica a vulgarização atual deste termo, ocorre em território brasileiro e não em terras paraguaias. Em meados da década de 80, quando centenas de famílias de brasileiros sem terras chegaram a Mundo Novo (MS), oriundas do Paraguai, ativaram a identidade "brasiguaios" como uma estratégia de homogeneização interna do grupo migrante e diferenciação frente a outros movimentos sociais já atuantes no Brasil (o MST, por exemplo).

O principal objetivo desses camponeses - ao enfatizar sua nacionalidade e seu sofrimento no Paraguai - era sensibilizar a opinião pública e pressionar o governo do Brasil para conseguir assentamento em território brasileiro (SPRANDEL, 1996; 2000). Porém, atualmente, para setores 
da imprensa (como a revista Veja e o jornal Folha de São Paulo), a identidade "brasiguaios" abrange todos os brasileiros que vivem no Paraguai. Ela serviria para definir desde o brasileiro sem terra no Paraguai, que hoje volta para o Brasil, até os brasileiros que continuam no Paraguai "lutando pela terra".

Mas, estaria o grande produtor de soja tão ameaçado de perder suas posses quanto o pequeno produtor? Essa vulgarização da identidade "brasiguaio", por parte da mídia, permite que integrantes das elites e da classe dominante locais, como os vereadores e o prefeito de San Alberto, também mobilizem politicamente a identidade "brasiguaios". Isso pode ocorrer como uma forma de encobrir, através do discurso, as grandes diferenças e desigualdades sociais existentes entre os imigrantes brasileiros residentes no Paraguai.

Declarações, reforçadas pela imprensa, de que está ocorrendo um "clima de limpeza étnica" contra todos os "brasiguaios", ou de como o Paraguai seria um novo Kosovo" (nas palavras de um vereador de San Alberto), fazem crer que, supostamente, a mobilização dos camponeses sem terras paraguaios (que tomaram a praça central e a prefeitura de San Alberto em 1999) são os principais responsáveis pelo retorno apressado ao Brasil de centenas de "brasiguaios". Na maioria das vezes, porém, para os representantes das classes dominantes, a identidade "brasiguaios" é tida como estigma para aquele que a carrega. Os "brasiguaios" que retornam ao Brasil são tidos como os fracassados, os miseráveis, os sem terra, incapazes etc.

Não resta dúvida que os camponeses sem terra paraguaios, mesmo que de forma velada, têm mobilizado sua identidade nacional, utilizando de forma estratégica o sentimento de pertencimento ao território do Paraguai para fortalecerem sua resistência frente à presença de agricultores brasileiros (chamados genericamente de "imperialistas" em San Alberto). Porém, em um Paraguai ainda recentemente democratizado, contraditoriamente, à medida que os camponeses sem terras atuam, parecem reforçar ainda mais a hegemonia dos grandes agricultores de soja, ou seja, de uma pequena fração, altamente globalizada, dos imigrantes brasileiros que residem no Paraguai.

Isso ocorre porque os camponeses paraguaios, segundo a Pastoral do Migrante, depois de receberem as terras ocupadas pelo movimento "campesino", tendem a ser relegados pelo governo paraguaio à própria sorte, isto é, sem incentivos técnicos, financeiros ou orientação de qualquer natureza para a produção ou formação de cooperativas. A tendência é que eles abandonem ou vendam as propriedades conquistadas para os grandes produtores de soja brasileiros, os mesmos que se dizem prejudicados por esse movimento social.

Mas a supremacia econômica de poucos agricultores e a grande influência cultural brasileira é acompanhada, como vimos em todas as localidades, por um grande drama sócio-político dos brasileiros mais pobres, causado pela falta da documentação necessária para oficializar residência no Paraguai. Por conseguinte, a maioria dos imigrantes tem que estar às voltas com o controle de sua mobilidade espacial e as extorsões que envolvem uma máfia nacional que lucra com a cobrança de propinas aos imigrantes estrangeiros (leia-se: brasileiros) sem a carteira do migrante ou com vistos temporários fora de validade.

Para representantes da Pastoral do Migrante em San Alberto e Foz do Iguaçu, a generalização da identidade "brasiguaios" acaba desencadeando uma crise jurídico-política. São milhares os brasileiros sem documentação no Paraguai e o governo brasileiro não estaria interessado em assumir o problema desses imigrantes ilegais, envoltos genericamente sob a condição de "brasiguaios". O "brasiguaio" seria então um indivíduo que não é nem brasileiro, nem paraguaio, ou seja, trata-se de uma "não-identidade", isto é, nomearia "gente que não tem nem pátria nem território". Os representantes da Pastoral do Migrante defendem, por isso, a troca do termo "brasiguaios" pelo termo "brasileiro residente no Paraguai". Caminhar-se-ia, desta forma, para uma explicitação maior da real condição de cidadania do migrante.

Gostaríamos de acrescentar que, assim como adquiriu uma forte carga de estigma, pela 
própria emergência histórica em meio aos "retornados" sem terra, a identidade "brasiguaio" também pode ter uma outra leitura simbólica, na medida em que incorpora uma condição híbrida, ambivalente e, portanto, muito rica, no cruzamento entre múltiplas identidades. Embora mais raros, encontramos alguns brasileiros que defendiam esta condição de "brasiguaio" exatamente na definição defendida pela Pastoral do Migrante: "sou brasiguaio porque sou brasileiro que mora no Paraguai". Mais do que a palavra, é fundamental que se mudem os significados, ou seja, neste caso, os estigmas que ela carrega. Tarefa às vezes mais difícil do que a própria mudança na condição concreta de não-cidadão.

Se a dinâmica identitária indica constantes mobilizações sociais e políticas entre imigrantes e população local, as redes de relações sócio-geográficas também podem nos dar uma idéia de como a dinâmica de imigração brasileira transgride os limites do Estado paraguaio e se projeta, ignorando muitas vezes os limites internacionais. Aí, o "brasiguaio" ou o "brasentino" pode ser, efetivamente e por várias razões, "aquele que vive dos dois lados da fronteira". Como bem se expressou Bruno Latour, é a rede que permite compreender melhor os processos sociais contemporâneos, por manifestar maior flexibilidade e historicidade. Ela revela o caráter dinâmico, relacional, e supera a idéia de uma identidade fixa, bem definida. Através das redes, neste caso muitas delas bem concretas (v. quadro 1), a identidade pode ser transgredida, reconstruída, reavaliada. Aí fica muito claro o seu caráter não simplesmente híbrido mas sobretudo maleável, descontínuo e, muitas vezes, temporário.

\section{REDES TRANSFRONTEIRIÇAS "BRASILEIRAS” NOS VIZINHOS DO MERCOSUL}

\section{TIPOS DE REDES CARACTERÍSTICAS GERAIS}

Econômicos legais $\quad$ Tratam-se das redes mais conhecidas e que se reproduzem há muito tempo entre os dois lados da fronteira, envolvendo o comércio de produtos (especialmente a soja. na caso paraguaio, o arroz, no caso argentino e uruguaio, e, nos três países, o gado). Muitas vezes são os mesmos empresários brasileiros que possuem estabelecimentos (empresas individuais, cooperativas) dos dois lados da fronteira. No caso do pampa argentino é uruguaio é um processo bastante antigo e que envolve inclusive figuras conhecidas do mundo político, como João Goulart e Leonel Brizola. Ressaltem-se também os circuitos financeiros, cada vez mais pronunciados, envolvendo aqui tanto operações legais quanto ilegais.

Ideológico-culturais

Os vínculos de ordem cultural-identitária mantidos entre os migrantes brasileiros nos países vizinhos e destes com o Brasil representa um amálgama fundamental na sua manutenção enquanto grupo. A utilização do idioma português e a difusão dos veículos de comunicação brasileiros são instrumentos da reprodução destes laços. Em áreas como San Alberto e Santa Rita, no Paraguai, Colônia Alicia e Colônia Aurora, na Argentina e Vila Encina, no Uruguai, o português (ou o espanhol "carimbado" pelo português, como dizem os uruguaios) é o principal idioma de comunicação. Além disso, rádios locais têm programações exclusivamente em português (vide a Pioneira 93.5 em San Alberto) e as redes de rádio e televisão brasileiras muitas vezes são mais difundidas que as dos países vizinhos. Ao nível da cultura e da identidade regional é muito representativo o avanço dó tradicionalismo gaúcho em localidades paraguaias, com Centros de tradições Gaúchas (CTG) em Santa Rita e San Alberto (aqui com o nome "híbrido" de "Centro de Tradições Guaranis"), vinculados, à rede do gauchismo paranaense, pois pertencem à região tradicionalista de Guarapuava, no Paraná. 


\begin{tabular}{|c|c|}
\hline Parentesco & $\begin{array}{l}\text { Fortes laços afetivos e de parentesco são mantidos entre os mígrantes } \\
\text { brasileiros e seus familiares que vivem, principalmente, na região Sul do } \\
\text { Brasil. Muitos laços familiares são mantidos pela continuidade dos } \\
\text { casamentos com habitantes das áreas de origem do migrante. São constantes, } \\
\text { assim, as viagens transfronteiriças, nos dois sentidos da fronteira. A província } \\
\text { Argentina de Misiones, por exemplo, serve de passagem para brasileiros que } \\
\text { habitam o sul do Paraguai. facilitando assim o contato com a região de origem } \\
\text { no noroeste do Rio Grande do Sul. }\end{array}$ \\
\hline Movimentos sociais & $\begin{array}{l}\text { Redes de movimentos sociais também se articulam como redes } \\
\text { transfronteiriças. Ë marcante a atuação do Movimento dos Trabalhadores Sem } \\
\text { Terra (MST) e da Pastoral do Migrante, especialmente no Paraguai. Diversos } \\
\text { representantes do MST, em La Paloma e San Alberto, têm orientado e } \\
\text { encaminhado "brasiguaios" para acampamentos no oeste do Paraná e sul do } \\
\text { Mato Grosso do Sul. A Pastoral do Migrante, baseada em Foz do Iguaçu (PR), } \\
\text { atua na obtenção de carteiras de imigração e apoio jurídico para brasileiros } \\
\text { ilegais no Paraguai. Também há contatos entre o MST e a associação de } \\
\text { pequenos produtores argentinos. Fazendeiros uruguaios revelam temor com a } \\
\text { possibilidade da entrada do MST no país, a partir de Bagé (RS). }\end{array}$ \\
\hline Políticos-eleitorais & $\begin{array}{l}\text { Existem milhares de eleitores que, embora residam em território paraguaio, } \\
\text { argentino ou uruguaio, continuam votando no Brasil, pois mantêm seus } \\
\text { títulos eleitorais brasileiros. Vide Foz do Iguaçu, onde se calcula que cerca de } \\
10 \text { mil "brasiguaios" tenham participado das eleições (A Gazeta do } \\
\text { Iguaçu, 10/09/1996). Muitos vereadores no Brasil (em cidades como Foz } \\
\text { do Iguaçu - PR e Dionísio Cerqueira - SC) são eleitos graças a promessas } \\
\text { feitas a migrantes brasileiros no Paraguai e na Argentina, oferecendo } \\
\text { assistência médica em hospitais ou vagas em escolas. }\end{array}$ \\
\hline Serviços & $\begin{array}{l}\text { Muitos migrantes recorrem aos. serviços de educação e saúde no Brasil, } \\
\text { principalmente no caso paraguaio, onde estes serviços geralmente são mais } \\
\text { precários, gerando assim fluxos temporários bastante intensos ao longo } \\
\text { da fronteira. Por outro lado, a condição de dupla cidadania (formal) pode } \\
\text { tomar-se uma estratégia para o usufruto de benefícios como os financiamentos } \\
\text { à produção, ora demandados em território brasileiro, ora no país } \\
\text { vizinho. Muitos também, mesmo residindo no outro país têm aposentadoria e } \\
\text { benefícios previdenciários garantidos pelo Estado brasileiro. }\end{array}$ \\
\hline Econômicas ilegais & $\begin{array}{l}\text { Embora elas nem sempre envolvam migrantes, estas redes atuam fortemente } \\
\text { como formas de reinserção ou reinclusão diante do forte desemprego e da } \\
\text { precariedade do trabalho. Destacam-se o contrabando de drogas, madeiras, } \\
\text { produtos agrícolas, automóveis etc. O rio Paraná, via lago da represa de Itaipu, } \\
\text { é o espaço mais utilizado pela contravenção e o crime organizado entre o } \\
\text { Brasil e o Paraguai. Outra rede ilegal que envolve máfias brasileiro-paraguaias } \\
\text { é a da prostituição. No caso argentino, presença maior de reservas florestais. é } \\
\text { frequente o contrabando de madeira-de-lei através de rios coam o Peperi- } \\
\text { Guaçu e o Uruguai. Produtos valorizados nos dois lados da fronteira, como o } \\
\text { arroz (produzido no Uruguai e Argentina) e a soja (produzida no Paraguai), } \\
\text { também participam de redes de comércio ilegal. É conhecido o caso da soja } \\
\text { brasileira contrabandeada para o Paraguai e que volta para ser exportada como } \\
\text { soja paraguaia pelos portos brasileiros. }\end{array}$ \\
\hline
\end{tabular}

FONTE: Pesquisa "A Região frente aos processos de Globalização e Fragmentação: a formação de uma região transfronteiriça entre os países vizinhos do Mercosul”. Elaboração Rogério Haesbaert e Marcelo Santa Bárbara

Ao participar desta multiplicidade de redes transfronteiriças o migrante brasileiro manifesta, objetivamente, sua condição "trans-identitária". Esse processo, como podemos ver pelo quadro, 
sinaliza transformações naquilo que tem caracterizado os territórios, num sentido tradicional e, com elas, da própria concepção de identidade territorial.

Territórios têm sido pautados, ao menos em tese, por concepções de limites/fronteiras e de uma identidade dotada de uma certa estabilidade, especialmente no caso dos territórios nacionais. Talvez em função da complexa geograficidade desenhada pela dinâmica de imigração brasileira nos vizinhos do Mercosul, sejamos forçados, como sugerimos em Haesbaert (1997), a trabalhar com duas "lógicas espaciais" distintas, porém articuladas, a "lógica territorial tradicional" e a "lógica reticular".

A "lógica territorial tradicional" é expressa por áreas onde as relações sociais estão delimitadas e reguladas de forma a serem estabelecidos recortes espaciais contínuos e contíguos que servem como quadro de referência para a ação dos agentes sociais. Tal tem sido o modelo de ordenamento territorial por excelência dos Estados nacionais modernos. Aí, a identidade territorial tende a legitimar ou a ser legitimada pelas fronteiras político-territoriais, aparecendo como uma "mancha de óleo", contínua, preenchendo todos os espaços e pretendendo atingir igualmente todos os seus habitantes. A lógica da vida dos migrantes em áreas transfronteiriças questiona esses pressupostos.

O padrão reticular de organização do território envolve relações complexas, de caráter descontínuo e não necessariamente excludentes. Um dos casos mais evidentes é o das redes transfronteiriças que aqui analisamos. O migrante é aquele que melhor vivencia a ambigüidade dessas duas lógicas territoriais: ao mesmo tempo que se depara com o controle rígido das barreiras fronteiriças internacionais, convive com múltiplas redes de solidariedade, de trocas comerciais, culturais e até mesmo políticas, de caráter transfronteiriço. Sua identidade é sempre uma identidade múltipla, cambiante, "em rede", uma identidade ambivalente, como a de "brasiguaio", ou híbrida - um indivíduo que se sente fazendo parte de dois (ou mais) territórios ao mesmo tempo. Parece claro, desta forma, que o estudo das migrações, especialmente pelo seu viés cultural, permite obter importantes contribuições para o estudo das novas territorialidades em formação no mundo contemporâneo.

\section{IDENTIDADE E MIGRAÇÃO EM ÁREAS TRANSFRONTEIRIÇAS}

Resumo: Os estudos sobre migrações adquirem crescente importância no mundo contemporâneo e também no Brasil, que se insere em circuitos como o das migrações transfronteiriças com os vizinhos do Mercosul. Este processo é aqui analisado sob a ótica do conflito ou do jogo de identidades culturais e sua participação na construção de novas territorialidades, especialmente as redes transfronteiriças.

Palavras-chave: Identidade, Migração, Redes, Mercosul.

\section{LDENTITY AND MIGRATION IN FRONTIER AREAS}

Abstract: The studies about migrations become very important in recent times. Brazil is also in international migration circuits, like the frontier migrations with neighbour countries of Mercosul. This dynamic is studied through the concept of identity as a conflict or a play and its participation in the making of new territorialities, specially those of frontier networks.

Keywords: Identity, Migration, Networks, Mercosul.

\section{BIBLIOGRAFIA}

BAYART, J. (1996) L'illusion identitaire. Paris, Fayart.

BERGER, P. e LUCKMAN, T. (1983) A Construção Social da Realidade. Petrópolis, Vozes.

BOURDIEU, P. (1997) O poder simbólico. Rio de Janeiro, Bertrand Brasil.

CANCLINI, N. (1997) Consumidores e Cidadãos Conflitos Multicfllturais de Globalização. Rio de Janeiro, Editora UFRJ.

CARDOSO DE OLIVEIRA, R. (1976) Identidade, Etnia e Estrutura Social. São Paulo, Pioneira. 
CASTELLS, M. (1999) O poder da identidade, Rio de Janeiro, Paz e Terra. A sociedade em rede. Rio de Janeiro, Paz e Terra.

ELIAS, N. (1994[1939]) O processo civilizador. Rio de Janeiro, Jorge Zahar.

HAESBAERT, R. (1988) RS: Latifúndio e Identidade Regional. Porto Alegre, Mercado Aberto. (1997) Des-territorialização e Identidade: a rede "gaúcha" no Nordeste. Niterói, EdUFF. (1999) Identidades Territoriais. In: Rosendhal, Z. e Corrêa, R. (orgs.) Manifestações da Cultura no Espaço. Rio de Janeiro, EdUERJ.

HALL, S. (1997) Identidades Culturais na Pós-modernidade. Rio de Janeiro, DP\&A

KOHLHEPP, G. (1999) A incorporação do espaço fronteiriço do leste do Paraguai na esfera de influência brasileira. In Potthast, B. et al. (orgs.) El espacio interior de América del Sur: geografis, historia, política, cultura. Centro de Estudios Latinoamericanos de la Universidad Católica de Eichstätt, série A: Actas, 19, Vervuert, Iberoamericana, Frankfurt, Madrid.

LATOUCHE, S. (1996) A ocidentalização do mundo. Petrópolis, Vozes.

LATOUR, S. (1996) Nunca fomos modernos. Rio de Janeiro, Ed. 34.

LÉVI-STRAUSS, C. (org.) (1977) L'identité (seminaire interdisciplinaire). Paris, Quadrige-PUF.

MARTINS, J. (1997) Fronteira: a degradação do Outro nos confins do humano. São Paulo, Hucitec.

ROBERTSON, R. (1999) Globalização. Petrópolis, Vozes.

SANTA BARBARA, M. (2001) Des-caminhos brasileiros em terras paraguaias: territórios e jogos de identidades. Dissertação de Mestrado, UFF.

SOUCHAUD, S. (2000) La formation d'un espace "bresiguayen" dans l'est du Paraguay Migrations pionnières brésiliennes et organizations socio-espatiales dans i'oriente du Paraguay. Tese de Doutorado, Univ. de Poitiers.

SPRANDEL, M (1992). Brasiguaios: Conflitos e Identidades em Fronteiras Internacionais. Tese de Mestrado, Rio de Janeiro: Museu Nacional.

(1996). Brasileiros de Além-Fronteira: Paraguai. In: Pastoral do Migrante et al. (org.). $O$ fenômeno migratório no limiar do século XXI. Petrópolis, Vozes.

TODOROV, I. (1993) Nós e os Outros. Rio de Janeiro, Jorge Zahar Editores.

WAGNER, C (1989). Brasiguaios: Homens Sem Pátria. Petrópolis, Vozes. 